\title{
O processo de produção de sentidos no universo do consumo: uma abordagem discursiva
}

\author{
Ronivaldo Moreira de Souza' \\ http://orcid.org/0000-0002-2124-9986 \\ I - Universidade Paulista \\ São Paulo (SP). Brasil
}

Resumo: Aceitar a metáfora dos objetos de consumo como signos é admitir que eles estabeleçam uma relação na qual os sentidos são intercambiáveis não apenas entre objetos, mas também entre os objetos e os sujeitos. Partindo da perspectiva de Baudrillard, que os considerou como signos, propomos uma reflexão teórica em busca de uma resposta plausível para a questão de como se dá o seu processo de produção de sentidos na sociedade de consumo. Por meio de pesquisa bibliográfica, colocamos em diálogo teóricos do consumo, da linguagem e do discurso investigando a imbricada relação entre os sujeitos e os objetos de consumo.

Palavras-chave: signos; consumo; produção de sentidos; análise do discurso.

Abstract: The production of meanings process in the universe of consumption: a discursive approach - To accept the metaphor of objects of consumption as signs is to admit that these objects establish a relationship in which the meanings are interchangeable, not only amongst objects but also between objects and subjects. From Baudrillard's perspective, who considered the objects of consumption as signs, we propose a theoretical reflection that seeks a plausible answer to the question of how the object's production of meaning process occurs in consumer society. Through bibliographical research, we place in dialogue consumption theorists and language and discourse theorists to investigate the imbricated relationship between the subjects and the objects of consumption.

Keywords: signs; production of meaning; consumption; discourse analysis.

\section{Introdução}

A natureza dicotômica da mercadoria foi percebida por Marx logo no início do século XIX. Mesmo quando o pensamento econômico ainda concebia a mercadoria como 
um objeto cujas propriedades visavam satisfazer necessidades de ordem natural, Marx já apontava para a sua dimensão imaterial, seu campo da fantasia. Para o autor, o primeiro valor da mercadoria emana da sua utilidade e é inerente à própria constituição física do objeto (ferro, trigo etc.). Contudo, além desse valor de uso, ela possui um valor de troca que se origina do trabalho socialmente necessário para produzi-la (MARX, 1996, p. 165-166).

Marx pensou essa relação dentro dos limites da visão econômica e sob o prisma de uma concepção teórica de superestrutura versus infraestrutura, classe dominante versus classe dominada. Sob essa ótica, a parte imaterial da mercadoria surge como produto ideológico na superestrutura e é disseminada na infraestrutura através da arte, filosofia e religião, como uma espécie de justificativa do real. Em sua tentativa de tirar o véu que encobria o real e romper com essa ideologia de domínio sobre a classe trabalhadora, Marx se limitou a retomar a parte imaterial da mercadoria apenas quando necessário para reforçar seu argumento do real. Em outros termos, o falso era retomado sempre que se tinha necessidade de reforçar o verdadeiro em sua concepção teórica.

A principal fragilidade da teoria marxista - e aqui admitimos que Marx não tinha como objetivo central explicar as relações de consumo, mas sim as relações de produção - é que essa parte imaterial da mercadoria era concebida num vácuo espacial entre a superestrutura e a infraestrutura. O consumo parece ficar deslocado no tempo e no espaço e a dimensão fantástica da mercadoria disposta para consumo é pensada como instrumento ideológico de dominação. É exatamente nesse ponto que Baudrillard é enfático. A base que sustenta toda a sua construção teórica está na definição do lugar do consumo:

\begin{abstract}
A propósito, também podemos já definir o lugar do consumo: é a vida cotidiana. Esta não é apenas a soma dos fatos e gestos diários, a dimensão da banalidade e da repetição; é um sistema de interpretação. A cotidianidade constitui a dissociação de uma práxis total numa esfera transcendente, autônoma e abstrata (do político, do social e cultural) e na esfera imanente, fechada e abstrata do "privado". (BAUDRILLARD, 2008, p. 26 grifos do autor).
\end{abstract}

Essa premissa fundante no trabalho de Baudrillard nos leva a três pressupostos que norteiam as discussões nesta pesquisa: 1) é no cotidiano que os objetos de consumo adquirem sentidos, criando um sistema de interpretação e atribuição de significados; 2) é no cotidiano que a fronteira entre o social e o privado se torna fluída; 3 ) é no cotidiano que o abstrato e o concreto, o real e o simulacro se tornam complementares entre si.

\title{
Os objetos como signos
}

A vida cotidiana se alimenta das imagens e signos "multiplicados da vertigem da realidade e da história" (BAUDRILLARD, 2008, p. 27). É esse simulacro do mundo que torna a cotidianidade suportável, pois "a imagem, o signo, a mensagem, tudo o que 
'consumimos', é a própria tranquilidade selada pela distância ao mundo e que ilude, mais do que compromete, a alusão violenta ao real" (BAUDRILLARD, 2008, p. 26).

A sociedade de consumo não organiza a vida em função da sobrevivência, mas sim em função do sentido que dá à vida. Desta forma, o valor do "ser" sobrepuja o valor econômico (BAUDRILLARD, 2008, p. 41). As ponderações do autor nos conduzem à conclusão de que essa busca pelo sentido do ser cria um espaço semântico entre o social e o individual, o público e o privado. É nessa fronteira fluída que os objetos assumem a condição de signos.

O signo é formado pelo significante (a parte material) e o significado (a parte conceitual). Se em um primeiro momento a teoria de Baudrillard é relevante por definir o lugar do consumo, em um segundo momento ela se destaca por definir o que é consumido nos objetos:

nunca se consome o objeto em si (no seu valor de uso) - os objetos (no sentido lato) manipulam-se sempre como signos que distinguem o indivíduo, quer filiando-o no próprio grupo tomado como referência ideal quer demarcando-o do respectivo grupo. (BAUDRILLARD, 2008, p. 66).

Percebemos que nessa proposta Baudrillard consegue aglutinar em uma só teoria a dimensão competitiva e o jogo de classificação e diferenciação já apreendido pelos teóricos que o antecederam. Sua proposta teórica consiste em analisar o processo de consumo sob dois aspectos fundamentais: 1) como processo de significação e comunicação; 2) como processo de classificação e diferenciação social.

A antiga base de análise que via a mercadoria apenas como tendo uma função (satisfazer necessidades através de seu valor de uso) é insuficiente. Agora se faz necessário ver a mercadoria a partir do seu funcionamento. A mercadoria que serve como utensílio funciona como elemento de conforto, prestígio, status etc.

Nessa lógica dos signos, "os objetos deixam de estar ligados a uma função ou necessidade definida, precisamente porque correspondem a outra coisa, quer ela seja a lógica social quer a lógica do desejo" (BAUDRILLARD, 2008, p. 89). Em outros termos, o conforto pode pertencer ao sofá na sala de estar e ao automóvel em uma estrada acidentada; a saúde pode pertencer à nova droga farmacêutica descoberta graças a mais inovadora tecnologia e ao alimento orgânico que se gaba de ser isento de tudo isto. Sua conclusão é que "o objeto contemporâneo já não consiste em servir para alguma coisa, mas em significar; deixou de ser manipulado como instrumento, sendo utilizado como signo" (BAUDRILLARD, 2008, p. 151).

\section{O processo de produção de sentido dos objetos: uma abordagem discursiva}

Pensar nos objetos como signos exige um olhar sobre o processo de produção de sentidos que resulta da relação entre os objetos e entre os objetos e os sujeitos. 
Para além da descrição da função dos objetos nessa relação, está a tarefa de descrever seu funcionamento respondendo a duas questões de natureza muito mais profunda: como e por que eles significam.

\section{Os objetos como signos sob a perspectiva discursiva}

Primeiramente precisamos romper com o conceito de arbitrariedade do signo, que aparece implícito na teoria de Baudrillard e nos parece ter sido apropriada da obra de Saussure (1945, p. 93).

Saussure entendia que, no signo, a relação entre o significante e o significado se dava de forma arbitrária. Por exemplo, a palavra (ou o significante) "garrafa" evoca a ideia (ou o significado) do objeto: garrafa. Porém, não há nada no objeto garrafa que justifique seu significante. Outra palavra poderia ter sido usada para referir-se ao objeto, tanto é que em outros idiomas garrafa é representada por outros significantes: bottle, em inglês, ou bouteille, em francês. Assim sendo, essa relação entre significante e significado "privaria" - nesta concepção de signo arbitrário e linguagem transparente - o falante de determinada língua de criar palavras.

A principal crítica a essa teoria de Saussure é que ela prende o significado ao significante, pressupondo uma relação estável e permanente entre eles. Se por um lado o falante de fato tem restrições para criar significantes, por outro, a relação entre os falantes torna os sentidos tão fluídos que alguns significantes adquirem significados completamente distintos e só compreensíveis em um dado contexto de fala. Ilustremos isso com a palavra "bomba", por exemplo. Se um pauteiro de algum jornal se levanta na sala de redação e diz: "tenho uma bomba", o significante, por mais idêntico que fosse, não remeterá ao mesmo significado se essas palavras forem ditas por um soldado no campo de batalha. Dito de outra forma, fora do contexto a palavra não é signo, pois é o contexto que torna a palavra em signo.

Sendo assim, partimos de três pressupostos para fundamentar nossas considerações:

1. Os objetos, assim como os signos, não são "sinais" inertes, mas sim dialéticos, vivos e dinâmicos;

2. O processo de construção de sentidos dos objetos está ancorado numa conjuntura sócio-histórica-cultural;

3. A construção de sentidos dos objetos se dá em um processo mútuo no qual os sujeitos atribuem sentido aos objetos e os objetos dão sentido aos sujeitos.

Para sustentar essa visão dos objetos (signos), como elementos dialéticos, vivos e dinâmicos, recorremos a alguns princípios fundantes da análise do discurso, que é uma visão pós-estruturalista. Antes, porém, de avançarmos, vale lembrar que nos referiremos 
aos objetos como um texto ${ }^{1}$ cujo código é partilhado pelos parceiros da comunicação. Primeiramente, apropriamo-nos da teoria da enunciação proposta por Bakhtin, cujo objetivo principal é evidenciar que existe uma parte não verbal que é constitutiva de sentidos, em qualquer ato de comunicação.

A percepção de Bakhtin de que todo enunciado tem uma parte não verbal, que se se liga ao contexto da enunciação, rompe com a linguística estruturalista e defende que o sujeito "utiliza a palavra para trabalhar o mundo, e para tanto a palavra deve ser superada de forma imanente, para tornar-se expressão do mundo dos outros" (BAKHTIN, 1997, p. 208). Os significados não estão presos e fixados no código linguístico. A situação de enunciação em que o enunciado é produzido se torna um componente indispensável para a compreensão e explicação da estrutura semântica de qualquer ato de comunicação, ou seja, "se perdermos de vista os elementos da situação, estaremos tão pouco aptos a compreender a enunciação como se perdêssemos suas palavras mais importantes" (BAKHTIN, 2006, p. 132).

É a enunciação que orienta a forma como o locutor fará uso da língua, pois todo uso que fará da linguagem será direcionado para atingir seus objetivos específicos gerados pela situação de enunciação

Na realidade, o locutor serve-se da língua para suas necessidades enunciativas concretas (para o locutor, a construção da língua está orientada no sentido da enunciação da fala). Trata-se, para ele, de utilizar as formas normativas (admitamos, por enquanto, a legitimidade destas) num dado contexto concreto. Para ele, o centro de gravidade da língua não reside na conformidade à norma da forma utilizada, mas na nova significação que essa forma adquire no contexto (BAKHTIN, 2006, p. 93).

Da mesma forma, os significados dos objetos não podem ser dados a priori sem levar em consideração o contexto no qual eles significam. Os sentidos que emanam dos objetos não podem ser impostos pela publicidade, por mais persuasiva que seja. Eles resultam do constante trabalho de interpretação e atribuição de sentidos que a enunciação exige.

Uma das limitações do argumento de Baudrillard surge na relação direta que ele estabelece entre a publicidade e o significado dos objetos. Nessa perspectiva, a publicidade teria um conjunto de significados mais ou menos estáveis (tais como: status, conforto, felicidade, segurança etc.) e que sua grande sutileza estaria na alternância dos significantes para os mesmos conjuntos de significados. Em outros termos, o status, o conforto, a felicidade e a segurança poderiam estar tanto na máquina de lavar, quanto no automóvel.

1 Para a Análise do Discurso, um texto é qualquer elemento que contenha uma linguagem independentemente do código que utilize. Desta forma, um quadro pode ser um texto, assim como uma fotografia, um poema, um simples gesto etc. Sendo assim, o universo que se descortina diante do analista constitui para ele o desafio de analisar o texto, pondo em relação seu "código linguageiro" e as regras que possibilitam a sua produção de sentidos. 
Afirmamos, pelo contrário, que a grande estratégia do discurso publicitário é construir situações de enunciação fictícias por meio de um comercial em que os objetos signifiquem, naquele caso específico, aquilo que o anunciante deseja. Entretanto, entendemos que tudo o que ela pode de fato produzir são efeitos de sentido. Essa perspectiva nos leva ao segundo postulado que defendemos: o processo de construção de sentidos dos objetos está ancorado em uma conjuntura sócio-histórica-cultural.

\section{O processo de construção de sentidos dos objetos}

Percebemos, portanto, que os objetos na condição de signos são uma ponte lançada entre sujeitos socialmente determinados. Para melhor compreensão da nossa afirmação vamos retomar a teoria da enunciação e avançar para a teoria da intersubjetividade.

A enunciação tem uma natureza singular, sendo impossível de ser repetida, mesmo que os enunciados sejam idênticos. Portanto, para observar o processo de produção de sentidos em uma determinada situação de comunicação

é preciso levar em conta, simultaneamente, a enunciação - o evento único e jamais repetido de produção do enunciado. Isto porque as condições de produção (tempo, lugar, papéis representados pelos interlocutores, imagens recíprocas, relações sociais, objetivos visados na interlocução) são constitutivas do sentido do enunciado: a enunciação vai determinar a que título aquilo que se diz é dito. (KOCH, 1995, p. 13-14).

No centro de todo ato comunicativo que envolve uma enunciação está a relação que os parceiros da comunicação travam entre si. Isto nos leva ao segundo postulado fundante em Bakhtin: a teoria da intersubjetividade. Em outros termos, toda enunciação constitui um espaço único de trocas intersubjetivas.

Bakhtin propôs uma concepção dialógica da linguagem. O outro está presente em toda situação de enunciação e participa ativamente na construção de sentidos de qualquer discurso. Podemos afirmar que o outro

\footnotetext{
é ao mesmo tempo constitutivo do ser e fundamentalmente assimétrico em relação a ele: a pluralidade dos homens encontra seu sentido não numa multiplicação quantitativa dos "eu" ("sic"), mas naquilo em que cada um é o complemento necessário do outro. (TODOROV, 1997, p. 14-15).
}

Mesmo quando esse outro não é uma presença física na situação de enunciação, ele surge no imaginário do locutor, como um interlocutor ideal ao qual o discurso se destina. E até na sua forma idealizada, o interlocutor exerce coerções e interdições na produção do discurso do locutor 
Na realidade, toda palavra comporta duas faces. Ela é determinada tanto pelo fato de que procede de alguém, como pelo fato de que se dirige para alguém. Ela constitui justamente o produto da interação do locutor e do ouvinte. Toda palavra serve de expressão a um em relação ao outro. Através da palavra, defino-me em relação ao outro, isto é, em última análise, em relação à coletividade. A palavra é uma espécie de ponte lançada entre mim e os outros. Se ela se apoia sobre mim numa extremidade, na outra apoia-se sobre o meu interlocutor. A palavra é o território comum do locutor e do interlocutor. (BAKHTIN, 2006, p. 115).

Para estabelecer uma relação clara entre estes pressupostos teóricos e os objetos como signos, assumiremos a seguinte perspectiva: "todo consumo é cultural" (SLATER, 2002, p. 131 grifo do autor).

Nosso argumento se apoia em quatro questões que relacionam a cultura e os significados na sociedade de consumo. Primeiramente, todo consumo é cultural porque sempre envolve significado:

para "ter uma necessidade" e agir em função dela precisamos ser capazes de interpretar sensações, experiências e situações e de dar sentido a (bem como de transformar) vários objetos, ações, recursos em relação a essas necessidades. (SLATER, 2002, p. 131).

Esse primeiro argumento destrona a noção de que o consumo se dá na manipulação de um consumidor passivo, uma marionete nas mãos da publicidade. Se consumir exige interpretação e atribuição de sentidos, logo é uma ação que se filia à razão. Em sua proposta de uma teoria sociocultural do consumo, Canclini (1997) enfatiza que o consumo é um ato da razão que se subdivide em três dimensões: racionalidade econômica, racionalidade sociopolítica interativa e, por fim, a racionalidade integrativa e comunicativa que atenta para os aspectos simbólicos e estéticos. Para o autor essa necessidade de distinção simbólica que estimula o consumo, encontra no significado dos objetos, ao mesmo tempo, a divisão e a integração

Se os membros de uma sociedade não compartilhassem os sentidos dos bens, se estes só fossem compreensíveis à elite ou à maioria que os utiliza, não serviriam como instrumentos de diferenciação. Um carro importado ou um computador com novas funções distinguem os seus poucos proprietários na medida em que quem pode possuí-los conhece o seu significado sociocultural [...]. Logo, devemos admitir que no consumo se constrói parte da racionalidade integrativa e comunicativa de uma sociedade (CANCLINI, 1997, p. 56 grifos do autor).

Isso nos leva ao segundo argumento: todo consumo é cultural porque "os significados envolvidos são sempre partilhados. As preferências individuais são elas mesmas, formadas no interior de culturas" (SLATER, 2002, p. 131). Assim como nos signos (ou na palavra, por assim dizer), os objetos funcionam como pontes, pois seu processo de construção de 
sentidos depende da partilha entre o eu e o outro. A validade dos significados dos objetos só é possível porque sua interpretação é compartilhada e aceita na esfera sociocultural. Em outros termos, "os bens de consumo definitivamente não são meras mensagens; eles constituem o próprio sistema. Tire-os da interação humana e você desmantela tudo" (DOUGLAS; ISHERWOOD, 2004, p. 120).

Em terceiro lugar, as formas de consumo são todas elas culturalmente específicas, pois são "articuladas dentro ou em relação a modos de vida significativos e específicos" (SLATER, 2002, p. 131). Na condição de signos, os objetos não significam isoladamente, mas sim no arranjo e combinação que os sujeitos fazem deles. Assim como não se analisa um texto olhando o sentido estrito de cada palavra, mas atentando para a relação das palavras e o arranjo delas no conjunto do texto, os objetos precisam ser analisados em sua totalidade, observando os arranjos específicos que cada sujeito lhes dá por meio do uso que faz deles, e como esses arranjos Ihes atribuem sentidos culturalmente específicos.

Nada tem valor por si mesmo: qual a vantagem de um sapato sem o outro? Um pente para a calvície? Como o valor é conferido pelos juízos humanos, o valor de cada coisa depende de seu lugar numa série de outros objetos complementares. Em vez de tomar um objeto de cada vez, e encontrar a informação que ele transmite, como se fosse um rótulo indicando uma coisa, a abordagem antropológica captura todo o espaço de significação em que os objetos são usados depois de comprados (DOUGLAS; ISHERWOOD, 2004, p. 41).

Compreendemos, deste modo, a natureza dialógica do universo semântico dos objetos. Os sujeitos (re)configuram os objetos por meio do seu uso para comunicar uma mensagem sobre si ou sobre seu lugar no mundo, de acordo com suas intenções de comunicação e os objetivos visados por ele. Em todo esse processo de construção de sentidos, o outro participa ativamente moldando e redefinindo seu discurso.

Em quarto e último lugar, afirmamos que todo consumo é cultural porque o senso de pertença a uma determinada cultura está intimamente relacionado ao domínio dos códigos significativos desta cultura. Em outros termos,

é através de formas de consumo culturalmente específicas que produzimos e reproduzimos culturas, relações sociais e, na verdade, a sociedade. Ser um membro de uma cultura ou de um "modo de vida", em contraposição a simplesmente "manter-se vivo", implica o conhecimento dos códigos locais de necessidades e coisas (SLATER, 2002, p. 131).

Sem o domínio dos mesmos códigos, não há comunicação. Essa última característica do consumo engloba todas as anteriores, pois dominar um código é ter a competência de atribuir e interpretar significados em uma dada situação de enunciação, numa relação específica entre os parceiros da comunicação. O domínio do código exige do enunciador 
uma competência de organizá-lo de tal forma que produza os efeitos de sentido que ele deseja e exige do enunciatário a competência de decodificá-lo e ressignificá-lo de acordo com os crivos de seu contexto sociocultural.

Os argumentos até aqui elencados nos levaram à constatação de que os significados emergem de um dado contexto sócio-histórico-cultural e são investidos nos objetos. Porém, ainda nos resta uma pergunta: como os sujeitos atribuem sentidos aos objetos? Para entender essa dinâmica, precisamos recorrer às questões subjetivas que estão implícitas nessa relação sujeito/objeto.

\title{
A subjetividade e o processo de construção de sentidos
}

O constante processo de interpretação e atribuição de sentidos é constitutivo do ser humano. Somos ao mesmo tempo seres construtores de sentido e construídos por sentidos. Isso coloca a linguagem como elemento ontológico do ser humano.

De fato, é essa a tese defendida por Rafael Echeverría (2005, p. 21; tradução nossa) quando afirma que "a linguagem é, sobretudo, o que faz os seres humanos o tipo particular de seres que são. Os seres humanos, propomos, são seres linguísticos, seres que vivem na linguagem". Na proposta do autor, o ser humano se constitui de três domínios primários: o domínio da emoção, o domínio do corpo e o domínio da linguagem. Porém, desses três, a linguagem se mostra mais essencial, tanto pelo fato de que as emoções e as posturas do corpo só podem ser descritas - e, portanto, só ganham existência - pela linguagem, como pelo fato de que as emoções e posturas são elas mesmas formas de linguagem. Desse modo, podemos afirmar que "é precisamente através da linguagem que conferimos sentido à nossa existência" (ECHEVERRÍA, 2005, p. 21 tradução nossa).

Para a análise do discurso, a construção de sentidos só é possível na relação dinâmica entre identidade e alteridade, tendo como centro o espaço discursivo criado entre os parceiros da comunicação (BRANDÃO, 2004, p. 76). Porém, afasta-se da concepção subjetivista de sujeito, como algo dado a priori, um sempre/lá que é origem do dizer. A relação entre o sujeito e o signo para a construção de sentidos instaura um processo contínuo de interpretação e negação da interpretação

\begin{abstract}
Não há sentido sem interpretação e, além disso, diante de qualquer objeto simbólico o homem é levado a interpretar, colocando-se diante da questão: o que isto quer dizer? Nesse movimento da interpretação o sentido aparece-nos como evidência, como se ele estivesse já sempre lá. Interpreta-se e ao mesmo tempo nega-se a interpretação, colocando-a no grau zero. Naturaliza-se o que é produzido na relação do histórico e do simbólico (ORLANDI, 2005, p. 45-46).
\end{abstract}

Essas formulações têm base nas teorias do discurso sistematizadas por Pêcheux (1997). O autor afirma que tanto os sentidos quanto o sujeito são construções do discurso 
e nenhum dos dois é dado a priori. Ao tomar a palavra, o sujeito ocupa um lugar social e pautado pela formação ideológica e pela formação discursiva, constitui-se sujeito à medida que "constrói" o seu dizer.

Podemos afirmar que o sentido se constitui da relação entre o sujeito afetado pela língua e a história. No entanto, é o gesto de interpretação "que realiza essa relação do sujeito com a língua, com a história, com os sentidos. Esta é a marca da subjetivação e, ao mesmo tempo, o traço da relação da língua com a exterioridade: não há discurso sem sujeito" (ORLANDI, 2005, p. 47). É na interpretação do signo que a subjetividade torna-se objetivada e que, em retorno, os sentidos constituem a subjetividade.

\section{A questão da subjetividade nos objetos/signos}

Vamos aplicar as teorias expostas até aqui considerando os objetos como signos e o processo de produção de sentidos constitutivo desse sistema semântico. Comecemos por definir o consumo como "uma questão de como os sujeitos humanos e sociais com necessidades se relacionam com as coisas do mundo que podem satisfazê-las (bens, serviços e experiências materiais e simbólicos)" (SLATER, 2002, p. 102).

Essa definição nos possibilita falar de relações objetificadas, já que ao atuar sobre o mundo, "os indivíduos e as sociedades o recriam em relação às suas necessidades e projetos. Suas necessidades - sua subjetividade, os significados que atribuem ao mundo são "objetivados", assumem forma material, nos objetos" (SLATER, 2002, p. 103). Portanto, o mundo dos objetos revela a subjetividade humana na recreação do mundo, a partir da visão que se tem dele.

Porém, essa relação entre o sujeito e o objeto que culmina em subjetivação daquilo que é objeto e em objetivação daquilo que é subjetivo, revela um processo cuja origem se dá nas práticas sociais.

\footnotetext{
Os objetos são assimilados na experiência subjetiva dos indivíduos - ou da coletividade, sob a forma de cultura e produção - sendo apropriados às finalidades humanas. Selecionamos, usamos, fabricamos, possuímos e transformamos os objetos de acordo com metas, objetivos, desejos e necessidades postulados pelos sujeitos humanos. De certa forma, esse talvez seja o único significado claro do consumo: vemos o mundo e o assimilamos tanto intelectualmente quanto na prática à luz de projetos e desejos subjetivos (SLATER, 2002, p. 102).
}

O que queremos deixar claro é que essa relação sujeito/objeto não pode ser investigada reduzindo-se a questão do consumo a sujeitos que usam objetos. Assim como nos signos, o processo de interpretação simultaneamente constrói o sujeito à medida que este atribui sentidos. Por meio dos bens, os sujeitos se comunicam e compreendem o que se passa à sua volta, já que os bens são um sistema estruturado de significados, entender e 
fazer-se entendido constitui uma só necessidade deste processo comunicativo (DOUGLAS; ISHERWOOD, 2004, p. 149).

O mundo dos bens "é a forma que os seres humanos deram ao mundo através de suas práticas mentais e materiais; ao mesmo tempo, as próprias necessidades humanas evoluem e tomam forma através dos tipos de coisas de que dispõem" (SLATER, 2002, p. 104). É no ato de organizar os objetos/signos de acordo com sua necessidade de comunicação que ocorre a transformação do indivíduo em sujeito, pois é aí que ele se torna sujeito no e pelo discurso dos objetos/signos que utiliza. De acordo com o tempo e espaço de que dispõe, o sujeito usa o consumo para falar de si, da sua família, do lugar onde mora e do estilo de vida que leva. A forma como organiza estes objetos/signos depende do universo onde ele habita, e o universo onde ele habita só ganha sentido graças a esta organização dos objetos/signos (DOUGLAS; ISHERWOOD, 2004, p. 116).

Nesse ponto, o consumo passa não só a dar sentido à existência como a justificá-la. Bauman (2008, p. 26) chega a afirmar que o sujeito cartesiano metamorfoseou-se e agora é definido pela sua capacidade de consumir, definindo-se na síntese: "compro, logo, sou... um sujeito". Isso porque a relação do sujeito com o objeto/signo instaura um constante movimento de interpretação e negação da interpretação. Esse processo produz um efeito de soberania do sujeito/consumidor, que mascara uma via de mão-dupla: a subjetividade é objetivada nos objetos/signos, e os objetos ganham uma dimensão subjetiva; os sujeitos atribuem sentido aos objetos/signos, e o sentido dos objetos justifica a existência dos sujeitos.

Nas lojas, as mercadorias são acompanhadas por respostas para todas as perguntas que seus potenciais compradores poderiam desejar fazer antes de tomarem a decisão de adquiri-las, mas elas próprias se mantêm educadamente silenciosas e não fazem perguntas, muito menos embaraçosas. As mercadorias confessam tudo o que há para ser confessado, e ainda mais - sem exigir reciprocidade [...]. Pela simples docilidade elevam o comprador à categoria de sujeito soberano, incontestado e desobrigado - uma categoria nobre e lisonjeira que reforça o ego (BAUMAN, 2008, p. 26).

Apesar do tom apocalíptico da obra de Bauman, admite-se o efeito de negação da interpretação, já que as respostas às perguntas dos compradores pareciam estar nos objetos/signos o tempo todo, mesmo antes da compra. Porém, o que permanece oculto na relação dos sujeitos/consumidores com os objetos/signos, é que todas as respostas que os objetos têm para os compradores surgem de uma pergunta que os objetos fazem a eles: "quem sou eu para você?". Em outros termos, tanto as perguntas quanto as respostas dos sujeitos/consumidores partiram deles mesmos. Porém, isso fica oculto na relação com o objeto/signo, produzindo um efeito de que os significados estavam lá o tempo todo.

Esse processo de interpretação e atribuição de sentidos é que possibilita falar de personificação dos objetos, pois é assim que eles deixam de ser uma coisa para tornar-se 
uma "pessoa", cuja alma é uma construção subjetiva do comprador. O objeto/signo abriga a alma do sujeito/consumidor

O prazer [...] vem do fato de a posse jogar [...] com a singularidade absoluta de cada elemento, que nela representa o equivalente de um ser e no fundo do próprio indivíduo [...]. O objeto [...] é o único "ser" cujas qualidades exaltam a minha pessoa ao invés de a restringir. No plural, os objetos são os únicos existentes cuja coexistência é verdadeiramente possível, pois suas diferenças não os dirigem uns contra os outros, como é o caso dos seres vivos, mas convergem docilmente para mim e se adicionam sem dificuldades à consciência; (BAUDRILLARD, 2012, p. 96-97).

Nesse percurso teórico pudemos constatar que os significados não estão presos aos objetos, mas sim resultam de um processo de interpretação e atribuição de sentidos realizada pelos sujeitos/consumidores, em uma situação sócio-histórica específica. Porém, esse processo de atribuição de sentidos mascara o trabalho de interpretação fazendo com que os significados dos objetos se apresentem ao sujeito/consumidor como evidências e não como resultado de sua interpretação.

\section{Considerações finais}

Na contemporaneidade, as práticas de consumo extravasam o potencial utilitarista dos objetos e migram para a dimensão intangível e significativa. Há uma mudança de paradigma da relação necessidade/utilidade para a do desejo/satisfação. Os objetos de consumo passam a preencher não apenas espaços físicos da vida cotidiana, mas, principalmente, a dimensão subjetiva dos consumidores dando-Ihes sentido nas práticas sociais.

Desse modo, os estudos no campo de comunicação e consumo não podem mais se limitar à perspectiva de definir consumo a partir de como os sujeitos utilizam os objetos. É preciso avançar epistemologicamente buscando apreender a rede semântica e o universo de sentidos construídos na relação entre os sujeitos e entre os objetos e os sujeitos. É preciso ver o consumo como comunicação e os objetos como signos, como linguagem que articula as relações de comunicação na sociedade de consumo.

Ronivaldo Moreira de Souza é pós-doutorando em Comunicação Social pela UNIP (Bolsista integral CAPES/ PNPD). É doutor em Comunicação Social pela UMESP.

ronivaldomds@gmail.com 


\section{Referências}

BAKHTIN, M.M. Estética da criação verbal. São Paulo: Martins Fontes, 1997.

Marxismo e filosofia da linguagem. São Paulo: Hucitec, 2006.

BAUDRILLARD, J. A sociedade de consumo. Lisboa: Ed. 70, 2008.

O sistema dos objetos. São Paulo: Perspectiva, 2012.

BAUMAN, Z. Vida para consumo: a transformação das pessoas em mercadorias. Rio de Janeiro: Jorge Zahar, 2008.

BRANDÃO, H. H. N. Introdução à análise do discurso. Campinas: Ed. da Unicamp, 2004.

CANCLINI, N. G. Consumidores e cidadãos: conflitos multiculturais da globalização. Rio de Janeiro: Ed. UFRJ, 1997.

DOUGLAS, M.; ISHERWOOD, B. O mundo dos bens: para uma antropologia do consumo. Rio de Janeiro: Ed. UFRJ, 2004.

ECHEVERRÍA, R. Ontología del lenguaje. Santiago: Lom, 2005.

KOCH, I. V. A Inter-ação pela linguagem. São Paulo: Contexto, 1995.

MARX, K. O capital: crítica da economia política - Livro I. São Paulo: Nova Cultural. 1996.

ORLANDI, E. P. Análise do discurso: princípios e procedimentos. Campinas - SP: Pontes, 2005.

PÊCHEUX, M. Análise automática do discurso (AAD-69). In: GADET, F.; HAK, T. Por uma análise automática do discurso: uma introdução a obra de Michel Pêcheux. Campinas - SP: Ed. da Unicamp, 1997.

SAUSSURE, F. Curso de linguística general. Buenos Aires: Lousada, 1945.

SLATER, D. Cultura do consumo \& modernidade. São Paulo: Nobel, 2002.

TODOROV, T. Prefácio à obra de Bakhtin. In: BAKHTIN, M. M. Estética da criação verbal. São Paulo: Martins Fontes, 1997. 